\title{
Innovative solutions for Renewable Energy and Energy Efficiency in Jordan
}

\author{
Farah Dawoud $^{1 *}$, Abeer Jbour ${ }^{2}$, Ahmed Al-Salaymeh ${ }^{3}$, \\ Louy Qoaider ${ }^{4}$, Thomas Fink ${ }^{4}$ \\ 1 Solid waste management Department, Ministry of Municipal Affairs, Third Circle Amman11181, Jordan \\ 2 Quality Management Department, Elerha GmbH, Zarqa Free Zone 13134, Jordan \\ 3 Mechanical Engineering Department, University of Jordan, Amman 11942, Jordan \\ 4 German International Cooperation (GIZ), Dag-Hammarskjöld-Weg 1-5, 65760 Eschborn, Germany \\ * Corresponding author's email: farahdawoud@windowslive.com,
}

\begin{abstract}
The aim of this paper is to specify people's awareness, acceptance and needs for the Renewable Energy (RE) and Energy efficiency (EE) innovations in Jordan. This took place after having studied the most influential innovations on RE and EE in Germany, Spain and Turkey. Then, two suitable innovations were selected; in particular, PV mobile charger and sodium light unit regulator. Our research was based on the analysis of qualitative interviews and a questionnaire. The results showed that (53\%) are willing to buy PV mobile charger depending on its life cycle and efficiency even if it is expensive. About (89\%) of respondents realized that it is important to develop and support the EE innovative solution of using sodium regulator in lighting the streets by the municipalities, and about (49\%) would like to take practical steps for the RE and EE developments if they could. The results also show that all respondents are willing to pay extra cost to obtain green energy; $(20 \%)$ want the cheapest possible solution in this regard. the study results indicate that Jordanian people do expect more from the public sector about renewable energy production; whereas a large percentage $(63 \%)$ thinks that public sector should take the first step towards renewable energy production. The acceptance and awareness of the society on RE and EE innovations is one of the most important drivers towards the transition to RE and EE in Jordan.
\end{abstract}

Keywords: renewable energy, energy efficiency, socio-economic, innovations, pv mobile charger, sodium light unit regulator.

\section{INTRODUCTION}

Renewable energy is an attractive option for developing economies, as it relies on locally available energy resources, in addition to their environmental and social benefits.

In these days with high oil prices that linger due to the growing demand from rapidly industrializing countries, which is a major trigger inducing renewable energy innovation across the world (Bayer et al 2013). Therefore, the trick is to develop renewable energy products that are as reliable, convenient and safe as the current energy system at a price that is lower or at least competitive with it.
The success of any technological innovation is based on two main things; first, having government funding of the basic science and some of the research and development, second is commercialization of these technologies by the private sector, in order to make the transition to Renewable Energy (RE) possible and effective within a short period. However, in fact it is the most influential part in making these concepts spread widely in the country and become a way of living, where the goal of a clean, high-tech future is easier to promote than the goal of reduced consumption of energy due to higher taxes. A positive vision of an optimistic future is an easier sell than the predictions of flooding, famine and doom. In many 
cases, organizations and individuals could easily save energy but either they are unaware of the facts, or do not have the time or capital needed to invest in making their operations more energy efficient. On the other hand, adoption of renewable energy technologies requires the innovations that enhance the performance and reduce the cost of key energy forms, such as solar and wind, and as the renewable electricity generation continues to grow in different markets, including developing countries, innovative capacity may soon follow (Bayer et al 2013).

Due to the rapid growth of economics, Jordan is facing two main challenges regarding its energy situation: first, the increasing energy demand due to continuous growth of population and influx of the Syrian refugees; second, limited domestic resources to fulfill this demand; this is because of the lack of primary energy sources that will cause the reliance on imported energy, as seen in figure 1. The dependence on imported energy has grown through the last years, especially after the sabotage of the gas pipeline in Egypt that supported Jordan energy by the highest percentage in 2012. This complete reliance on foreign oil imports, makes Jordan consume a significant amount of the gross domestic product (GDP), and led the country needs to plan investments in renewable energy and energy efficiency projects.

The aim of this research was to study the most influential innovations of renewable energy and energy efficiency, on global level and then find the most suitable innovation which could be implemented in Jordan and support the transition towards RE, not to forget about clarifying the importance of awareness and acceptance of people. Our research depended on this link between the needs that leads to making innovations and the actual steps taken. Accordingly, two practical examples for both RE and EE innovations, which are using sodium light regulator for lighting the

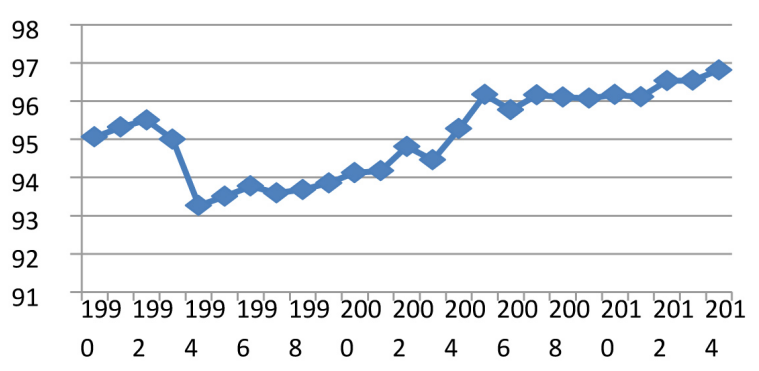

Fig. 1. Jordan Energy Import (\% energy use) (EIA, 2014) streets, and having a market for PV mobile charger, were studied in terms of the people awareness and acceptance.

\section{LITERATURE REVIEW}

\section{Innovations world wide}

Accelerating technological innovation in renewable technologies can contribute towards lowering the cost of renewables so that they can compete with conventional fossil fuel energy sources (IEA, 2010). Specifically, directing technological innovation away from the traditional fossil fuel technologies toward the renewable ones might be particularly effective in this regard (Noailly et al. 2015).

While industrialized countries have historically been the primary sources of renewable technology innovation, in recent years many developing countries, including China and India, have begun to play an important role as innovators in this field, but the question now is why some countries are more innovative than others. In a study about the global patterns of renewable energy innovation between 1990-2009; it was mentioned that at the heart of the economic literature on innovation, the theory of "induced innovation" is clarified which states that a change in relative price spurs innovation. Applied to environmental innovation, this suggests that an increase in the price of oil should result in an increase in technological advancement. The previous empirical work has attributed $25-50 \%$ of the improvement in the energy efficiency of home appliances to the increases in energy prices (Bayer et al. 2013).

Green technologies encompass a continuously evolving group of methods and materials, from the techniques for generating energy to non-toxic cleaning products. Therefore, the related innovation is increasing worldwide. Due to the fact that green innovation goals are increasingly part of national innovation and energy strategies for many developing leading countries such as Germany and other OECD (Organization for Economic Cooperation and Development), where their economies are giving priority to research and development $(R \& D)$ activities and incentives for the diffusion and adoption of green technologies.

Historically, regulations, together with subsidies and feed-in tariffs, have been the main policy tools for fostering market uptake of greener technologies. Recently, many countries have started 
using targeted demand-side innovation policies such as public procurement, standard-setting, and consumer policy to encourage demand for green technologies (OECD, 2016).

The Hype Cycle published by Gartner Group is an example showing the expectation of people to the emerging technologies to evaluate their significance, and it also shows on which development stage a certain technology is moving (Hype cycle, 2013) The assumption in this evaluation method is that a technology develops from innovation triggers, peak of inflated expectations, trough of disillusionment, slope of enlightenment, and finally reaches a plateau of productivity where the technology becomes mature and the market recognizes it as a profitable technology. Figure 2 shows the overall summary of some green technologies based on this Hype Cycle (Ahn 2014).

\section{Innovations in Germany, Spain and Turkey}

Innovations have a significant effect on the energy systems in many countries, such as Germany. A positive average effect of the German feed-in tariff schemes implies that the policies spur innovation (particularly, high-quality patents) in renewable energy technologies (Böhringer 2017). On the other hand, the role of citizens is very important also in achieving the transition to renewables in Germany. The rise of new, organized energy actors, specifically small-scale investors in renewables such as private households, farmers and citizen energy cooperatives has been one of the most striking features of the German energy transition process. According to a survey carried out by Trend: research $\mathrm{GmbH}$ and Leuphana Universität Lüneburg (2013) by the end of 2012, nearly

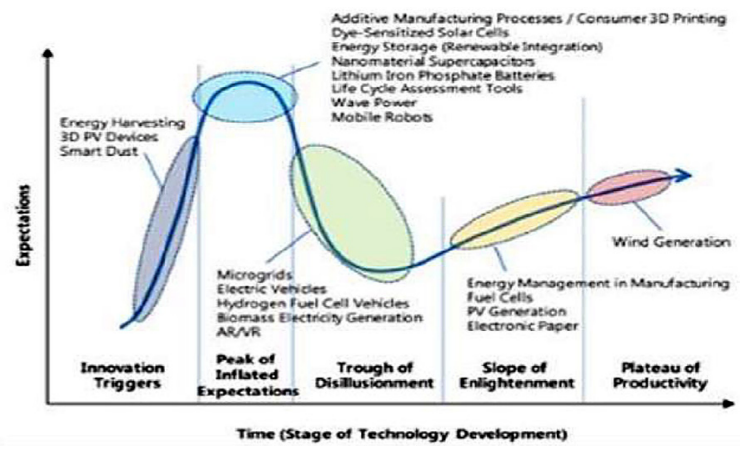

Fig. 2. Hype Cycle 2013 modified to show the development stages of research areas related to green manufacturing technologies (Ahn 2014) half $(46.6 \%)$ of the total renewables capacity installed in Germany was owned by citizens and citizen energy cooperatives (Fig. 3). The study defines more than one third of this capacity as „citizen energy in the narrow sense ${ }^{\text {ee }}$, i.e. it was set up by local and regional initiatives in which citizens have the majority of the decision making power (Beermann et al. 2017).

The example on innovations that has been studied involves the clean energy storage. Energy storage has recently come to the foreground of discussions in the context of the energy transition away from fossil fuels (Akinyele and Rayudu, 2014). Flywheel energy storage technology supports the expansion of renewable energies and ensures the stability of a grid fed with multiple intermittent energy sources (Wicki et al. 2017). In addition, Turkey is considered one of the most significant countries at global level in implementing the innovations. Turkey, for the first time using integrated approach, applied the Decision Making Trial and Evaluation Laboratory Model (DEMATEL) technique, integrated with Analytic Network Process (ANP) approach (Büyüközkan et al. 2017). In Spain it was found that the national and supra-national agencies encourage to innovate and setting hard targets for RE development and carbon emissions in 2020 and 2050 are critically dependent on multi-nationals, utilities and economic processes whose resilience would be undermined by these innovations (Hewitt et al. 2017).

On the basis of the above-mentioned studies and research, this paper investigates the people awareness, acceptance and needs of the RE and EE innovations in Jordan. In particular, PV mobile charger and Sodium light unit regulator. Moreover, it highlights the barriers and drivers for the transition towards RE and EE in Jordan.

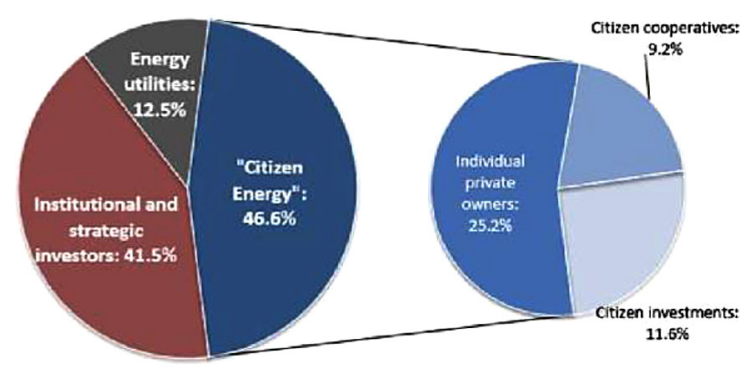

Fig. 3. Ownership structure of installed renewable energy capacity in Germany (2012) (Beermann et al 2017) 


\section{First Practical RE Innovation: PV mobile charger}

There has been significant growth of mobile phone market in recent years, and due to the fact that it has become an essential part of our lives; it requires charging the battery anytime and anywhere. However the disadvantages of mobile phone batteries limit their application. Their energy density can drop as low as $(200 \mathrm{Wh} / \mathrm{kg})$ and their technology seems to improve slower than other technologies. The abundance and widespread availability of solar energy make it the most attractive among other energies that can be feasibly extracted to be used as a solution to charge the batteries.

Batteries are often paired with solar panels to provide energy storage for the inherently intermittent power generation nature of solar panels. However, solar panels are non-ideal power sources, and the operating point at which maximum power is generated depends on many factors such as incident light (including any partial shading), temperature and panel aging. While discussing solar panels and power, terms such as maximum power point tracking (MPPT) and maximum power point control (MPPC) are often used. They change with the solar radiation, as illustrated in Figure 4 (Xiao et al. 2017) by insolation when the cell temperature is constant at $25^{\circ} \mathrm{C}$.

The solar power application to battery charging has been studied and experimental works regarding this matter have been done. One innovation of PV mobile charger that was useful for society was invented by (Varadarajan 2012), i.e. the Coin Based Universal Mobile Battery Charger, which is a novel method of charging mobile batteries of different manufacturers, using solar power. It was designed and developed for rural and remote areas. Where the grid power is not available all the time, in this design of coin

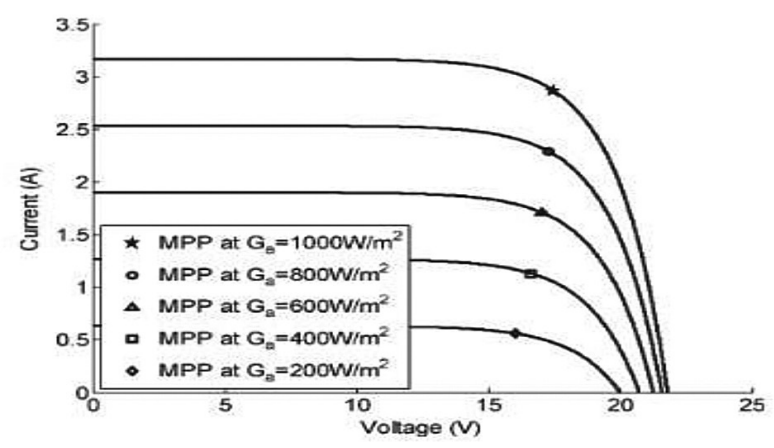

Fig. 4. Simulated I-V curves of BP350 influence based mobile charger, a fixed solar panel of size $(635 \times 550 \times 38 \mathrm{~mm}),(37 \mathrm{Wp})$ was used to charge the battery up to maximum ( $2 \mathrm{amp}$ ) in bright sun light. The user has to plug the mobile phone into one of the adapters and insert a coin; the phone will then be given a micro pulse for charging. However, it does not bring a mobile from 'dead' to fully charged state (Varadarajan 2012).

Another one was by (Al-Mashhadan et al. 2014) proposed a novel design for a solar-powered charger for low-power devices, where two power sources (AC and solar) were used. The design used only a few components so the system is cost effective, besides being highly portable (Al-Mashhadan et al 2014).

While searching through the market for PV mobile chargers, many options and many prices seem to be available and cost efficient to the end users, with prices between $4.5 \$$ to $70 \$$, and a variety of options from portable chargers to water proof power banks, as seen in Figures 5 and 6.

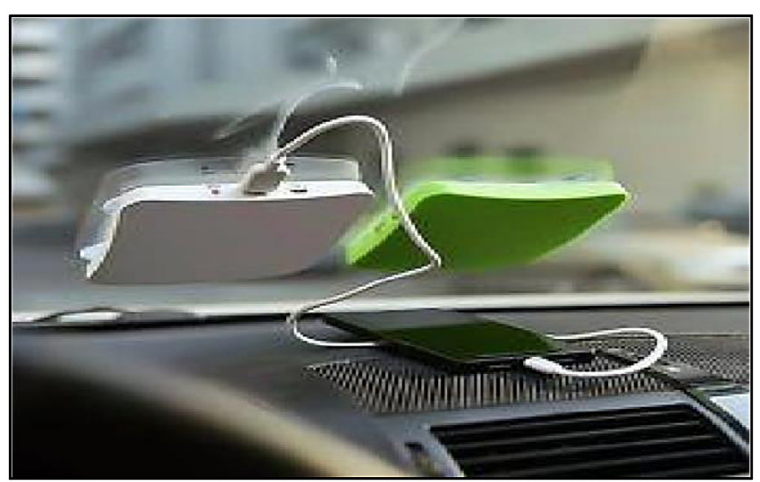

Fig. 5. $300000 \mathrm{mAh}$ Portable Solar Power Bank Dual USB Battery Charger Backup for Phone

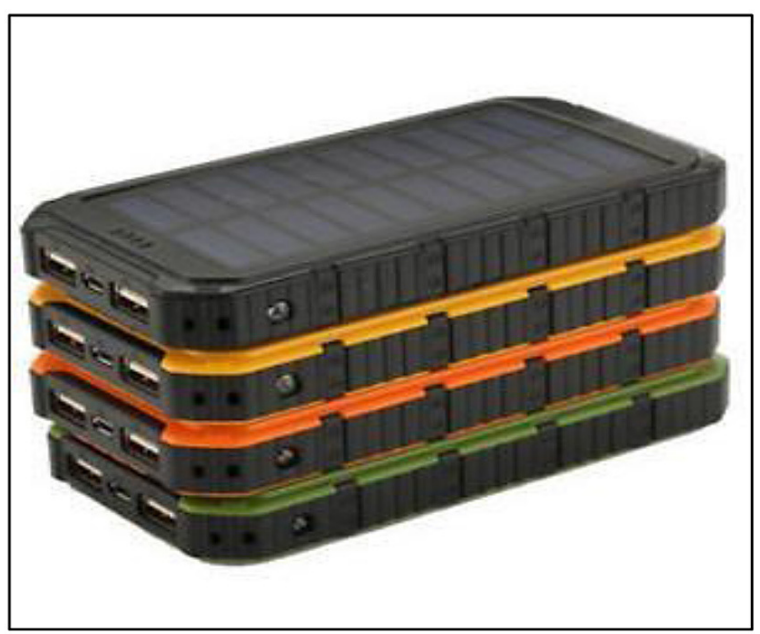

Fig. 6. 1800 mah Solar Mobile Power Bank Battery Portable Charger External Power Outdoor 


\section{Second Practical EE Innovation for Jordan: Sodium light regulator}

Energy efficiency has become a very important approach to save energy significantly at both national levels as well as at a local level, especially, in the developing countries such as Jordan. EE refers to the use of lesser energy input to deliver the same service (or, similarly, using the same amount of energy input to deliver more service) (IRENA, 2015). Thus, it plays a crucial role in reducing the consumption of energy by using different solutions / measures which are affordable and practical for use in different sectors, in particular in residential like installing building insulation, and in the municipal sector like using efficient lighting (e.g. LED lamps for street lighting). In this context, during the last (10) years, many initiatives have been implemented in Jordan in EE field as well as polices for supporting these initiatives. For instance, one of the supportive policies is the Jordan Energy Efficiency Action Plan (NEEAP) that has been prepared in 2013 and aimed at implementing good practice standards in policy making for energy efficiency (Becker et al., 2013).

Another example is the Jordan Renewable Energy and Energy Efficiency fund (JREEF), which was established in response to meet the needs of the Kingdom to invest in various sources of renewable energy and widen benefit in various sectors, such as residential, educational (schools), health (hospitals) as well as private, public, industrial and service sectors to achieve several objectives, and one of these objectives that is related to EE involved activate methods and procedures of energy efficiency and energy conservation in various sectors (MEMR, 2017). Many codes have been issued related to EE in buildings (i.e. energy efficiency buildings code, solar energy code, thermal insulation code and green building manual) (Tawalbeh 2016). On the other hand, many projects have been implemented in EE field, such as Aqaba residents' energy efficiency (AREE), where various EE measures were used (Tawalbeh 2016).

Consequently, EE plays a vital role in decreasing the consumption of energy, which means reducing the energy invoice, in particular the electricity invoice for the sectors and buildings that consume large amount of electricity. One of such these sectors and buildings is the infrastructure and service sector and the public buildings in the municipalities. Hence, all the municipalities in Jordan suffer from the electricity invoice, which accounts to more than (30\%) from their budget. The most consumption of electricity in the municipalities is from the street lighting. In fact, this is making the municipalities far away from its actual role, which is development. In other words, instead of disbursing the above mentioned percentage $(30 \%)$ in implementing development and investment projects that would improve the economic situation of the municipality as well as the whole society, this amount is used for paying the electricity invoice.

Therefore, the Ministry of municipal affairs in Jordan has supported the municipalities, by securing funding for the replacement of the old light units with LED units, which is a good and efficient solution for lighting. However, the process of replacing the old light units with LED units costs the municipalities a lot, which constitutes a financial burden for them.

Accordingly, one of the innovative solutions for street lighting is the Sodium Light regulator, which simply involves installing a regulator on the old unit (Sodium Light unit) instead of replacing it with a new LED unit. That means reducing the cost of purchasing new units and purchase controller pieces, which have lesser cost and will control the consumption of electricity according to the usage of the street. This innovative solution has been implemented in some municipalities in Spain and contributed to a significant reduction of electricity costs reaching (40)\% (memoria, 2017).

One of the experimental studies on the regulators was performed in Spain and aimed at presenting a high performance of a specific prototype of regulation and stabilization of luminous flux for public street lighting installations. It has been in operation in a real outdoor lighting installation for more than one year. When the lights are switched on for 10 hours a day, it would represent a consumption of $10,220 \mathrm{kWh}$ a year. The regulator is set up in order to operate during the off-peak hours, 6 hours a day. The consumption is reduced to $8,600 \mathrm{kWh}$. It means an energy saving of more than $1,600 \mathrm{kWh}$ a year (Blánquez et al. 2013). Figue 7 shows the Voltage stabilizer and regulator prototype (Blánquez et al. 2013).

The Sodium Light regulator works on two key concepts:

- Stabilizing: Public lighting installations experience considerable voltage variations throughout the night. These voltage variations 
can be as high as $10 \%$, increasing the energy consumption by $21 \%$. Stabilizing the light levels at nominal voltage results in substantial reductions of the energy consumption.

- Dimming: Public lighting installations generally maintain constant lighting levels throughout the night. Dimming the light levels after midnight, adapted to vehicular traffic and pedestrians on public roads, yields substantial savings in the energy consumption

Accordingly, a stabilizer-dimmer device allows the reduction of voltage to $175 \mathrm{~V}$ and therefore their consumption by up to $40 \%$ of the rated value (in High Pressure Sodium Vapour lamps) Blánquez et al. 2013). It is worth mentioning that the sodium light regulator is one of the suggested solutions that will be adopted and implemented in (3) Jordanian municipalities through technical and financial support from a European program (Qudra). These are (Ramtah municipality in Irbid governorate, Mafraq municipality and Al-Sarhan municipality in Mafraq governorate). Finally, this paper shows the possibility of using this solution in the municipalities. In addition, it shows the willingness of donors to finance such solution.

\section{MEHODOLOGY AND DATA ANALYSIS}

In order to measure the awareness and the acceptance of implementing renewable energy \& energy efficiency innovations in Jordan, we decided to use a survey questionnaire. This methodology helped to include people from different backgrounds to enrich the sample space and make the research results more substantial, reliable and

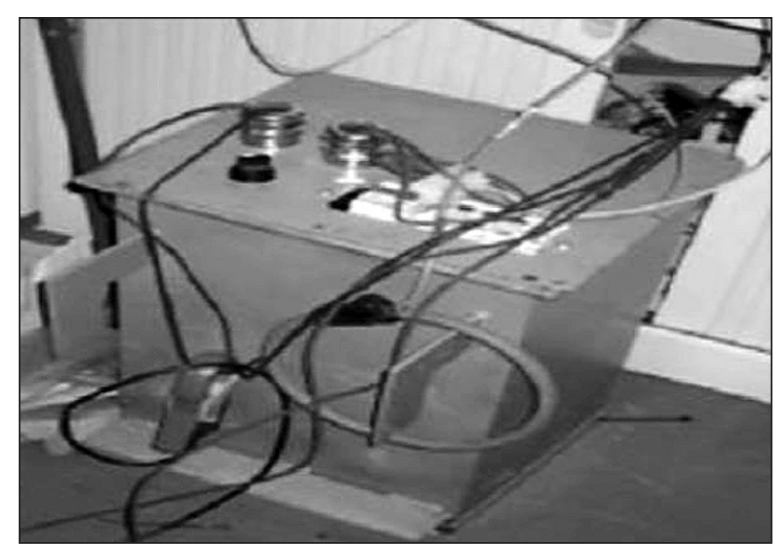

Fig. 7. The voltage stabilizer and regulator prototype [Blánquez et al. 2013] objective (Moula 2012). The survey was conducted through:

- First: conducting interviews with concerned entities representatives, to learn the existing implemented innovations in Jordan and to know the linkages and gaps between policies and the implemented innovations.

- Second: Distributing questionnaire representing all community categories (i.e. public sector, private sector, universities, NGOs, CBOs... etc.) in Jordan; to specify the awareness and the acceptance of the people as well as their needs for innovative solutions on RE and EE in terms of availability and affordability.

- Third: Data analysis.

\section{Interviews}

In this paper, we elaborated qualitative and significant interviews with concerned people at Ministry of Energy and Mineral Resources (MEMR), in order to:

1. Know who is responsible for preparing the proposal for an innovative project in RE and $\mathrm{EE}$; is it MEMR responsibility or is it the responsibility of any firm/ person, who is concerned and wants to implement an innovative project / solution?

2. Identify the policies that support the implementation of innovations in RE and $\mathrm{EE}$ in Jordan.

3. Highlight the existing innovations, which have already been implemented in Jordan.

In this context, three separated and specific interviews were elaborated with concerned people at Ministry of Energy and Mineral Resources (MEMR), namely: representative of renewable energy department, representative of Jordan renewable energy and energy efficiency fund (JREEF) and the team leader of renewable energy and energy efficiency program funded by European Union at MEMR. Each interview consisted of (4) main questions related to the role of the department / entity toward innovative solutions / projects in RE and EE, the possibility of supporting any person who has an innovative idea, the existing supportive policies and examples of innovative projects in Jordan which have been implemented or are in the process of implementation.

The main outcomes of the interviews were explained at the results section. 


\section{Questionnaire}

In order to identify the awareness and the acceptance of the people as well as their needs for innovative solutions on RE and EE in terms of availability and affordability, we developed a specific questionnaire. Since we are working on the research which is related to energy technologies, this could result in posing too technical or professional questions. We should avoid applying too technical and professional questions that would confuse the people answering the questions; this may make them not wanting to answer, consequently causing meaningless communications and results (Moula et al. 2013).

For this study, our survey consisted of 29 multiple choice questions and the last one was for the suggestions by people.

It comprised two parts; the first part was related to the information about participants' background variables like participants' age, job situation, etc. The second part was concerned with people awareness and acceptance of RE and $\mathrm{EE}$ innovations presented (PV charger and Sodium regulator for lighting mainly) and the people willingness to invest and support them, this included related information such as: perceptions, attitudes, usefulness, intention to use, cost, participant's position about the renewable energy technology, its applicability...etc.

We collected the survey results from all the group members by filling our questionnaire data in a web based link by Google forms to make it easier to distribute and fill. Afterwards, we started conducting the quantitative analysis by summarizing all the data and calculating the percentage of the choices for each question.

The respondents came from randomly different age groups. A total number of (204) people responded to the survey from different regions of the kingdom (North $(9 \%)$, Middle $(83 \%)$ and South (3\%)). (76) People were male and (125) female, (115) from age (18 to 30), (64) people from age (31 to 40), (22) people from age (41 to 60 ) and (1) person form age (60 and above). These age groups were chosen specifically to understand the role of age condition on social acceptability of renewable energy and energy efficiency innovations.

Majority of the participants were employed $(80 \%)$, whereas the second group of participants were students $(12 \%)$, and fewer participants were unemployed $(8 \%)$.
A qualitative conclusions based on the quantitative analysis can be drawn, as the percentage will indicate some problems and truth for the survey. In this study, the size of the sample was small but diverse. Such a sample cannot represent the voices and attitudes of all the Jordanian society about social acceptability of RE and EE innovations. However, it can be considered as a good starting point for extended future surveys.

\section{RESULTS}

\section{Interview results}

On the basis of the interview objectives, the results are as follows:

- There are concerned institutions in Jordan that support the adoption and implementation of innovative solutions / projects at national /institutional level (i.e. ministries, public institutions ... etc.) and at local /individual level (youth, women, privet sector ... etc.).

- There are set of polices, regulations and legislations that are available at Energy and Minerals Regulatory Commission (EMRC) website in details (EMRC, 2017). In addition, this website includes section called Ideas Bank, which allows any entity, institution or person to suggest any new idea that can be implemented in RE and EE. These policies support and encourage investors, public sector, private sector, people and all community categories to invest in $\mathbf{R E}$ and $\mathbf{E E}$ field. However, there is no specific innovative frame work that has been developed to adopt and implement innovations in RE and EE in Jordan.

- There are ideas for innovative projects for $\mathrm{RE}$ at national / institutional level in Jordan, such as the hybrid power plant (link the conventional power plant with renewable energy power plant, for instance photovoltaic or wind power plant). Moreover, there are innovative ideas for EE toward the green buildings, such as developing insulation material with specific standards to be used in windows and other for walls, in order to reduce the heat losses in buildings. Furthermore, in the transportation sector, which consumes the largest amount of energy, in 2016 it consumes about (48\%) among other sectors (residential, commercial.. etc.) from the total energy consumption in Jordan (MEMR, 2017) the hybrid cars and 
electrical cars were the most applicable innovative solutions in Jordan for this sector, since they do not only reduce the consumption of energy (fuel) but also reuce the carbon dioxide emission $\left(\mathrm{CO}_{2}\right)$ that effects the climate change.

\section{Questionnaire results}

\section{Background information of the respondents}

As shown in figure (8), there females prevailed in the sample (62\%) and figure (9) shows that selecting participants from different age groups is in order to have an idea of the impact of age on the results. In contrast to many earlier studies, in this survey we found that the level of support for renewable energy technology towards better environment seems to correlate with age, with older people being more supportive than others.

Figure (10) shows that $3 \%$ of answers were from non-Jordanian people, it does not necessarily reflect the situation of population in Jordan as the sample was not large but despite it showed that the non-Jordanian people express interest and respond to the survey concerning Jordan. Figure (11) shows that there were more responses from the middle region of Jordan (Mainly Amman and Zarqa). As there is a higher population share based on region in Jordan.

Figure (12) shows the level of education where the majority hold the Bachelor's degree. Figure (13) shows that most of the sample came from the employed group. This reflects the current socio-economic situation in Jordan. More

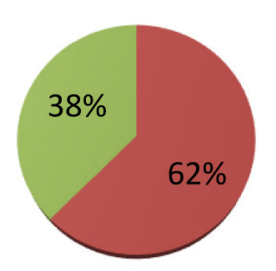

- Female

Male

Fig. 8. Q (1): Gender of respondents

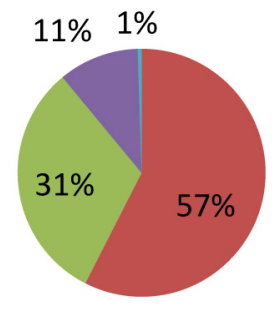

- 18-30

- $31-40$

- 41-60

61 and older

Fig. 9. Q(2): Age group of respondents generally, in respondents' current situation in terms of the employed, unemployed and students, there seems to be a positive correlation between income, and levels of support for different renewable energy technologies.

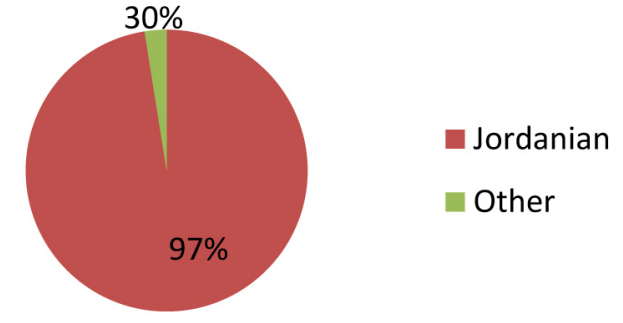

Fig. 10. Q(3): Nationality of respondents

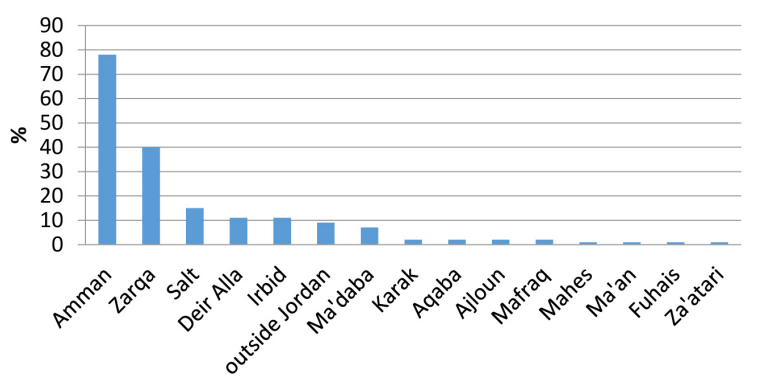

Fig. 11. Q(4): Location percentage of respondents based on cities in Jordan

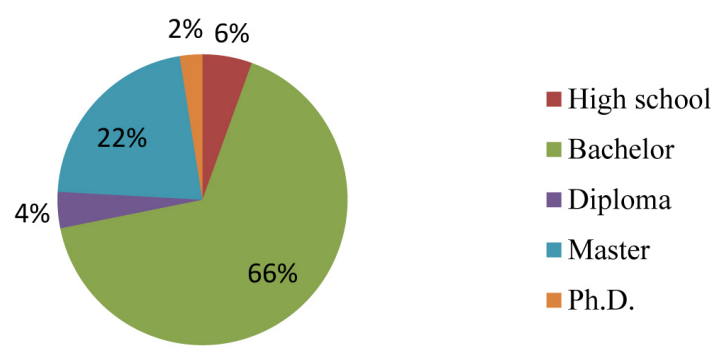

Fig. 12. Q (5): Level of education of respondents

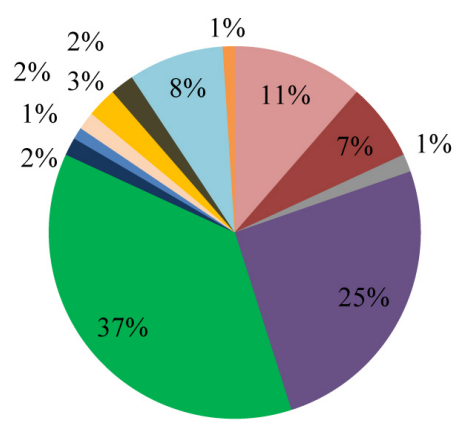

= Student
$\square$ Home worker
$\square$ Military
$\square$ Employee in
government
department.
Working in
private sector.
- Working in NGOs

Fig. 13. Q(6): Current job status of respondents 


\section{General respondents' awareness of RE and EE technologies}

Questions from (7) to (19) results, illustrated in figures from (14) to (26), show the awareness of people regarding the RE and EE. Approximately $(89 \%)$ as majority of respondents wants to save environmental resources. About (32\%) of respondents said that they have very good level of knowledge of RE, where only (2\%) said that they do not know anything about RE. (99\%) said that it is important which indicates the awareness about importance of RE. On the other hand, $(63 \%)$ of respondents suggested that the first step towards renewable energy production should be the responsibility of the public sector. However, (18) people, i.e. about $(9 \%)$ of the respondents, were mainly from youngest age group (18-30) said that RE is not important as well as EE is not important, Figures (18), (25) show the results of these question, respectively.

It is worth mentioning that $(47 \%)$ of respondents have a very good level of knowledge of EE, and (98\%) said it is important. Surprisingly, (89\%) chose the right answer regarding $\mathrm{EE}$, which is that it basically comprises "ideas, solutions and technologies that are related to decrease energy consumption, such as replacing the old lighting units with LED units, and is not related to generating electricity" this percentage is compatible with the previous ones related to the knowledge on EE. Additionally, (98\%) said that it is important, which indicates the awareness about the importance of EE.

In addition, in reference to the question that related to the willingness to pay for green energy, around $(31 \%)$ of respondents are prepared to pay up to $(5 \%)$ more extra cost for using green energy, $(20 \%)$ want the cheapest possible solution and around (28\%) are willing to pay up to (10\%) of extra costs.

$(57 \%)$ said it is useful, where (27\%) said they do not know if it useful or not and (16\%) said it is not useful. In reference to the question asking

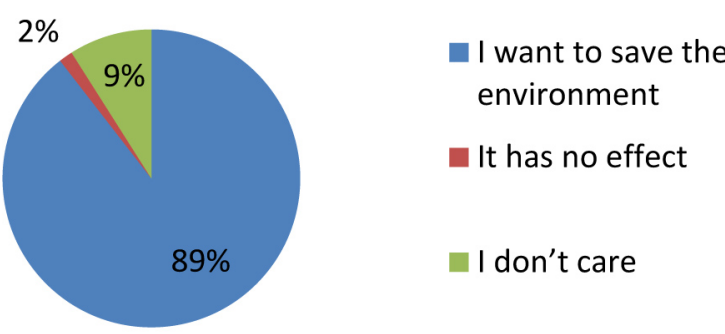

Fig. 14. Q(7): Level of knowledge about climate

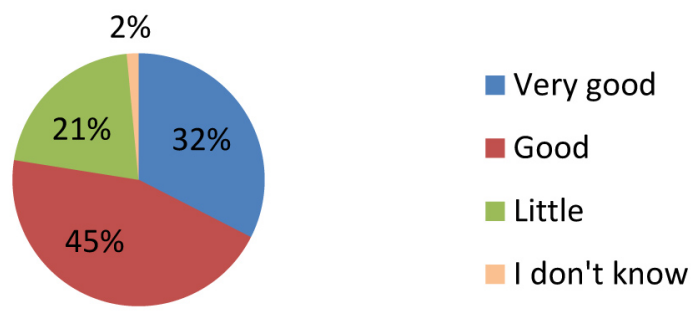

Fig. 15. Q(8): Level of knowledge about Renewable Energy

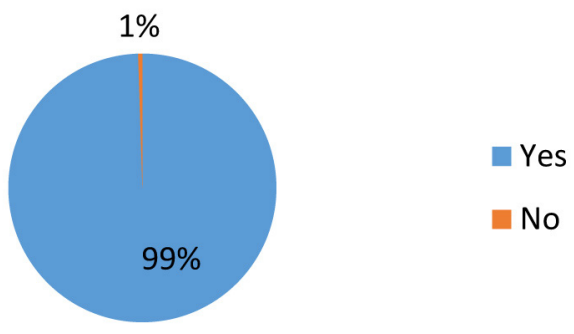

Fig. 16. $Q(9)$ : Importance of RE

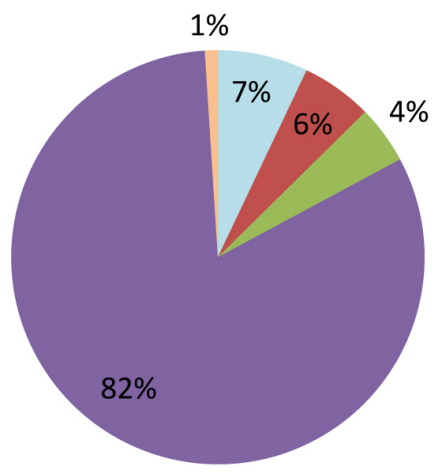

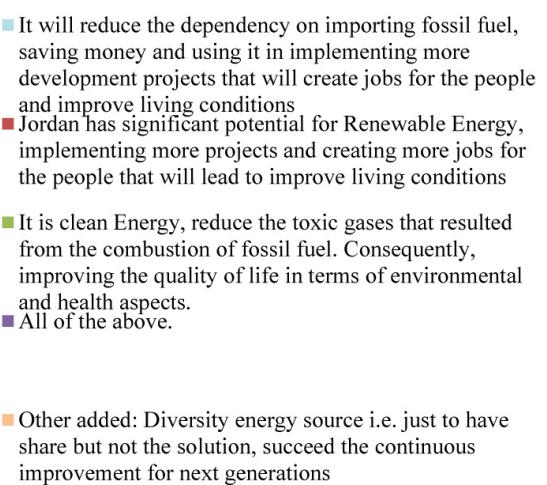

Fig. 17. Q (10): Why RE is important 


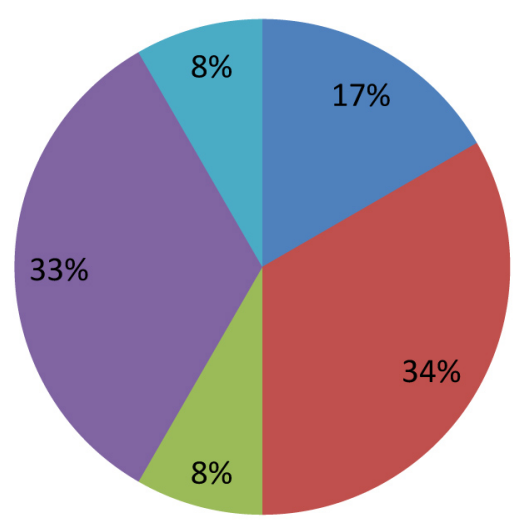

Because it is new and there is no enough experience in Jordan to implement Renewable Energy projects.

- Because its technologies are very expensive.

Because it has no effect on improving the production of Energy in Jordan, especially generation of electricity.

All of the above

Fig. 18. Q (11): Why RE is not important, if the answer in the previous question was [No]

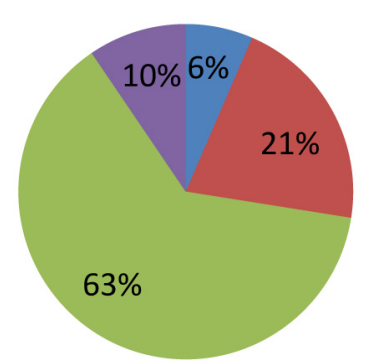

Fig. 19. Q (12): Who should take the first step towards renewable energy production?

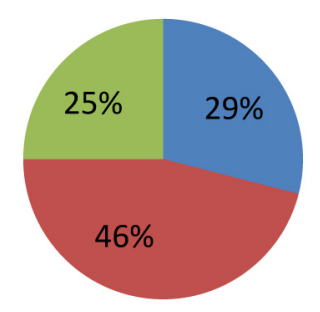

Energy

distributors

- Energy producers

- Public sector

Privet sector

Fig. 21. Q (14): Level of knowledge about Energy Efficiency

$4 \% 7 \%$

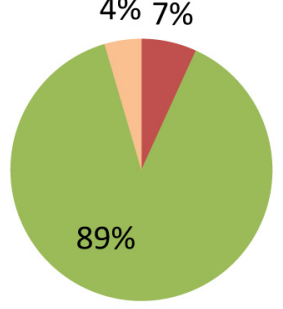

There is no difference

Energy Efficiency is part of Renewable Energy

Energy Efficiency has many ideas,solutions and technologies that related to save energy consuming, such as replacing the Old lighting units with LED units, and doesn't related to generating electricity

Energy efficiency means using less energy to provide the same service. Renewable energy is energy that is collected from renewable resources, which are naturally replenished on a human timescale, such as sunlight, wind, rain, tides, waves, and geothermal

Fig. 22. Q (15): What is difference between Energy Efficiency and Renewable Energy? 


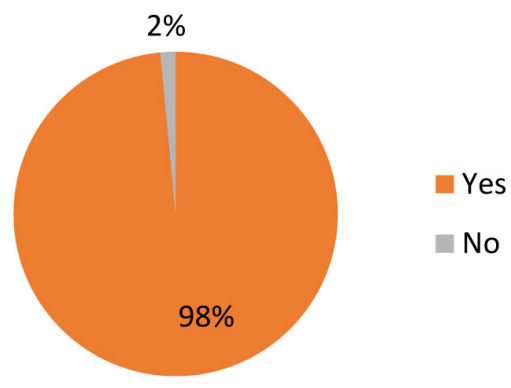

Fig. 23. Q (16): Energy Efficiency Importance
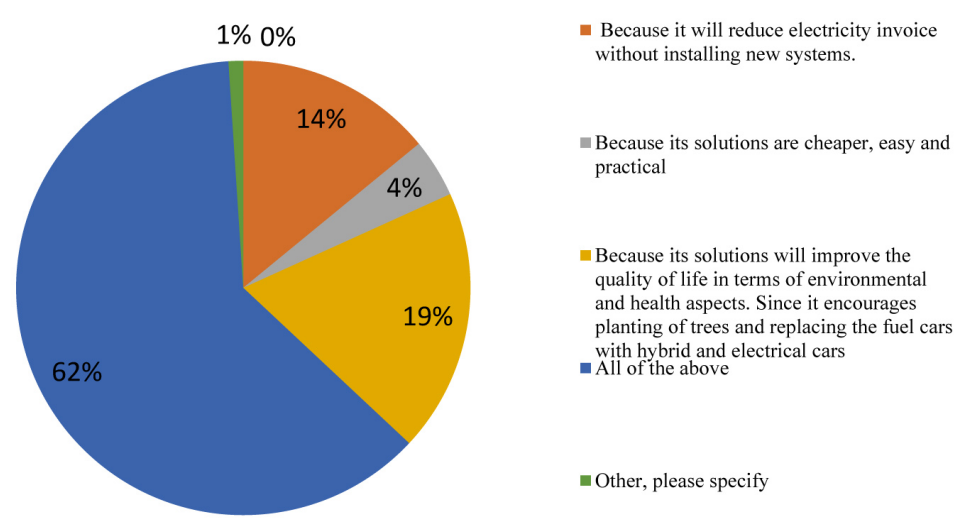

Fig. 24. Q (17): Why Energy Efficiency is important?

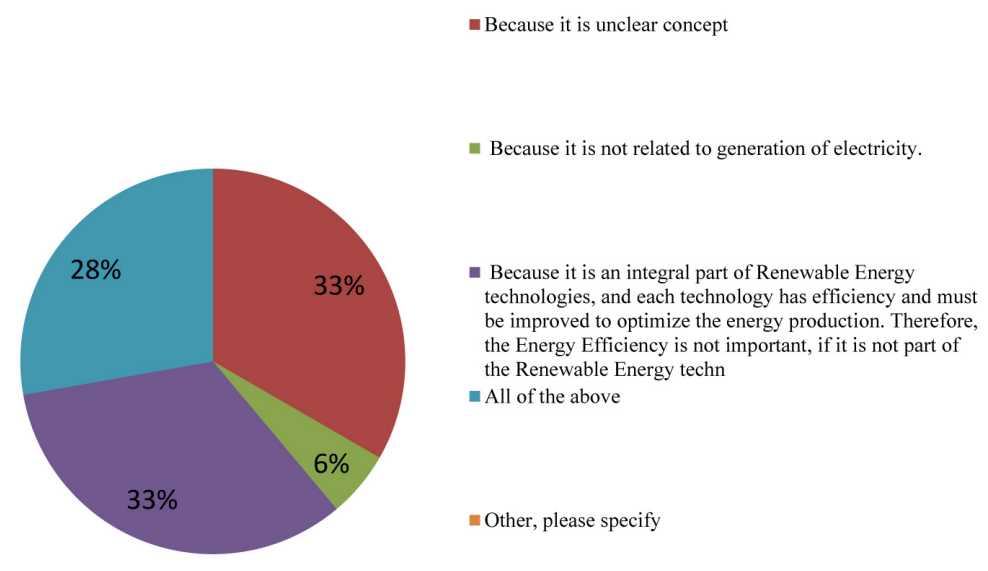

Fig. 25. Q (18): Why is not Energy Efficiency important?

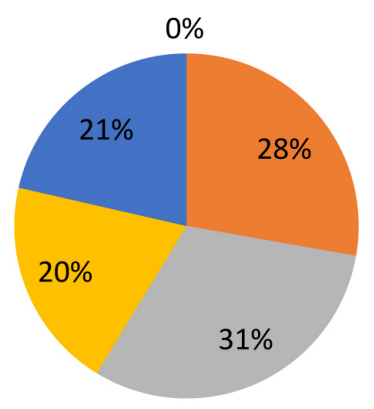

$$
\begin{aligned}
& \text { Up to } 10 \% \text { more } \\
& \text { Up to } 5 \% \text { more } \\
& \text { I want the } \\
& \text { cheapest solution } \\
& \text { I am not willing to } \\
& \text { pay }
\end{aligned}
$$

Fig. 26. Q (19): Willingness to pay for green energy 
about the appropriate place for using this solution, (45\%) answered this solution could be used anywhere, (27\%) answered at streets only, and they are the sample from public sector and about $(27 \%)$ of the respondents said they do not know where it should be used.

Furthermore, (49\%) of the respondents said that if they would be a donor, they will invest in the sodium regulator for lighting solution, while (89\%) will encourage the municipalities to use this innovative solution.

\section{Specific respondents' awareness of innovative solutions in RE and EE}

These set of questions were put to focus on the innovation part of RE and EE, and play both roles of being educative and testing the knowledge that the respondents have regarding PV mobile charger and sodium regulator for lighting.

Questions from (20) to (29) results shown in the figures from (27) to (36). Moreover, there was another question $(\mathrm{Q} 30)$, which was to give the respondents an opportunity to give suggestions or express opinion about RE and EE innovative solutions.

The suggestions were listed at the end of this part, where $(20 \%)$ of the sample answered this question, There were some interesting suggestions from all different group ages, the noticeable thing is that the middle age group (31-40) and employed group took this part seriously and actually gave very good suggestions. $(89 \%)$ of the respondents said that the PV mobile charger is an innovative solution. Surprisingly, if the price of the PV mobile charger is between JOD (21-50), $(14 \%)$ said they would buy it even with that high price, where $(53 \%)$ said it depends on the lifecycle and efficiency of it, and (28\%) said it is expensive. Regarding the suggested innovative

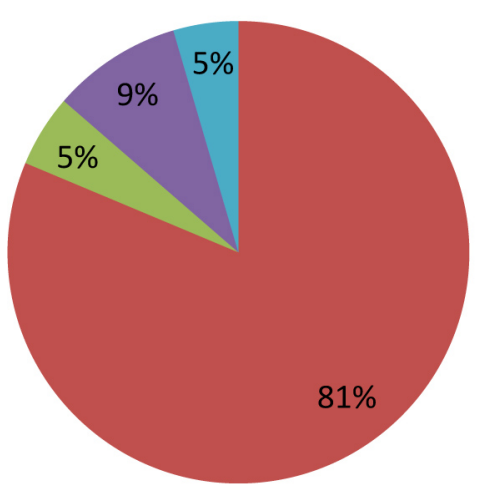

solution for EE, which is the sodium regulator for lighting, about (84\%) of the respondents said that it an innovative solution.

Here we would like to list all the suggestions that came from the $(20 \%)$ of the respondents, where they suggested ideas for innovative solutions according to their needs:

1. Using renewable energy in charging cars on the way.

2. Keep RE Projects on large scale and increase the share in electricity mix slowly not like what is going now with MEMR.

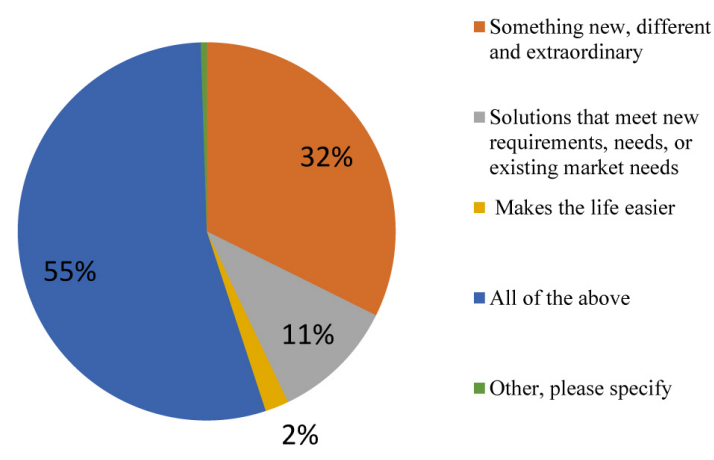

Fig. 27. Q (20): Innovation meaning

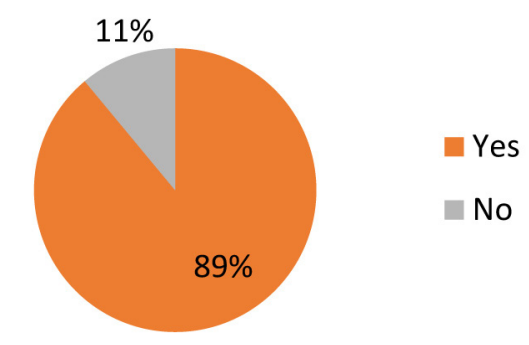

Fig. 28. Q (21): Is the Photovoltaic (PV) mobile charger an innovation

Fig. 29. Q (22): Is PV mobile charger useful? 


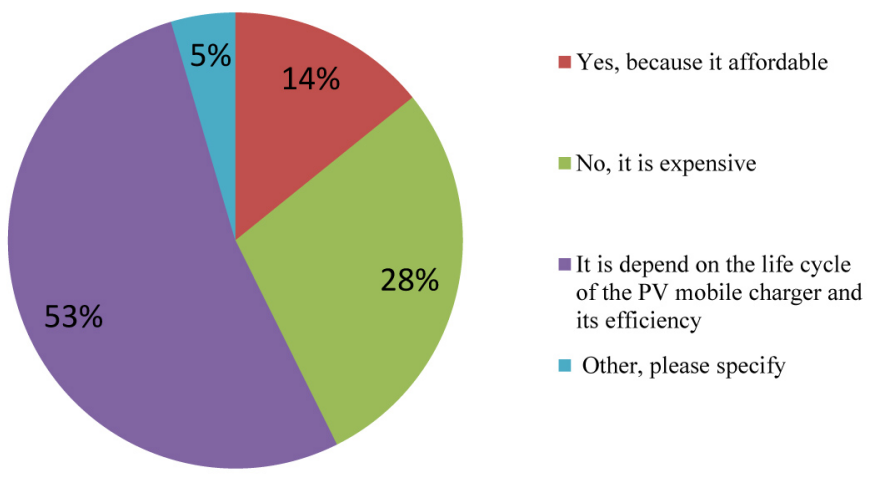

Fig. 30. Q (23): Is the price of the PV mobile charger (21 - 54) JOD affordable?

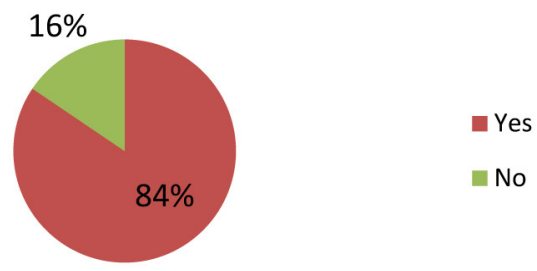

Fig. 31. Q (24): Is the sodium light unit regulator (controller) an innovation?

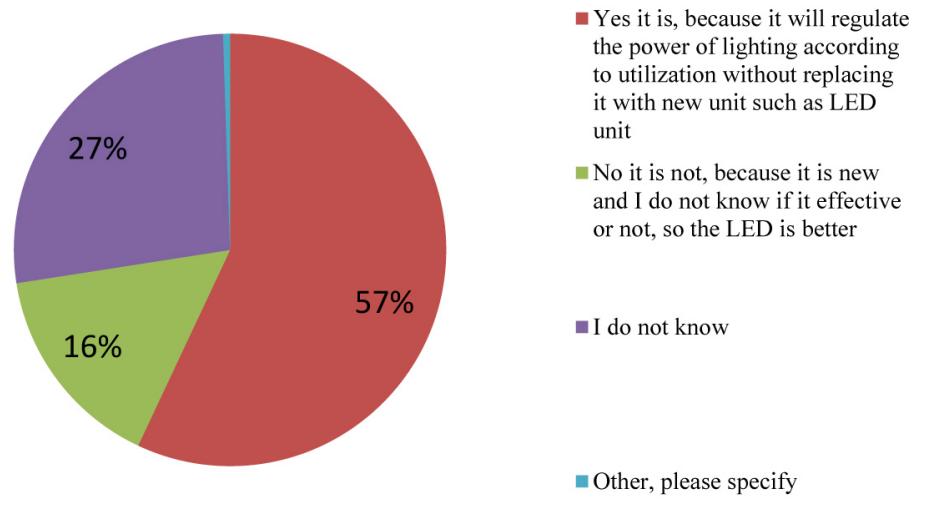

Fig. 32. Q (25): Is the sodium light unit regulator (controller) useful?
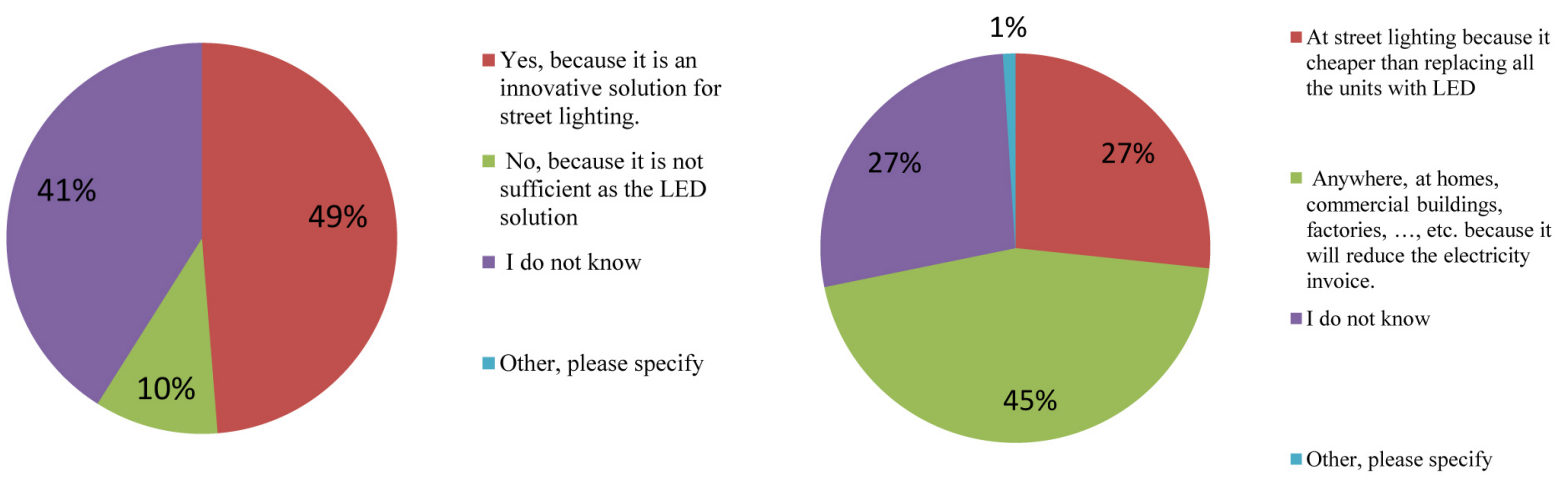

Fig. 33. Q (26): Donors interest in the sodium light unit regulator (controller) investment

Fig. 34. Q (27): The best place for using the sodium light unit regulator (controller) 


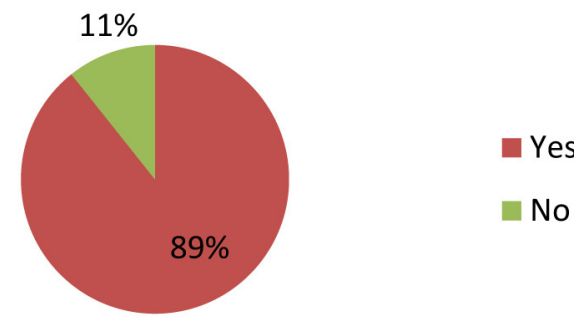

Fig. 35. Q (28): Donors interest in the sodium light unit regulator (controller) investment

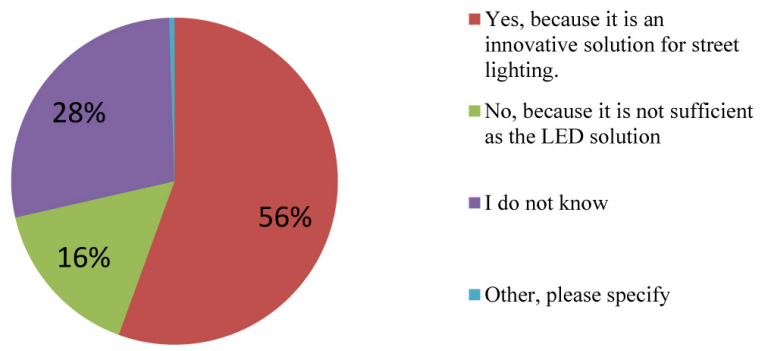

Fig. 36. Q (29): Municipalities interest in the sodium light unit regulator (controller) investment

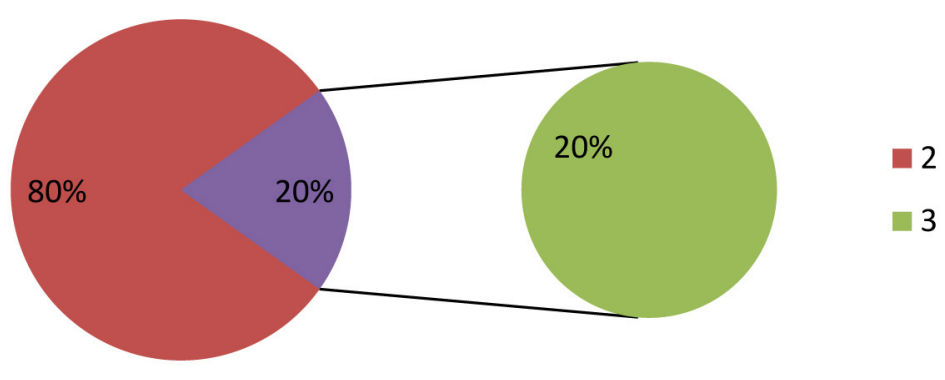

Fig. 37. Q (30): People suggestions

3. Be affordable, accessible, applicable and friendly used.

4. Make a solid plan with achievable target to all Jordanian to reduce energy consumption.

5. Used all types of Renewable energy resources like PV, wind, biomass, geothermal and doing an energy audit for all facilities and buildings to improve the energy efficiency as whole.

6 . Something that does not need constant maintenance and can benefit not only a specific target audience that focuses on the environment, but also any business or consumer interested in investing in a source of energy that will save $\mathrm{him} / \mathrm{her}$ money in the long run.

7. There are many ways to use the power of sun... Nowadays there are complete buildings and cities which are using the renewable energy for almost everything. Anything now can be operated on the power of sun, wind.

8. Increasing awareness regarding RE \&EE in all sectors (i.e. schools, universities, media... etc.). Adopt all ideas for the above mentioned. Increasing innovation solutions and select the more efficient solutions.

9. Using the distribution networks or deploying micro grid for better using of renewable energy sources.

10. You should not be giving us the solution in your questions! I sense it was a questionnaire that is targeted to a result you want not to measure real people's knowledge.

11. Innovations in the way the message is delivered to people.

12. There is no general energy efficiency measure, each problem has a specific solution.

13.Establish a government mechanism to determine that new buildings are licensed only if renewable energy is used and cost a few financial means to reduce licensing fees in order to engage the private sector in partnership with the public sector by providing potential and tools, thereby raising awareness of the importance of energy and thus providing the necessary facilities for its dissemination.

14. Lantern on renewable energy.

15. Governments embrace and act on these ideas at all levels.

16. Use solar cells to provide daytime traffic signals and if you can use battery systems to use them in the evenings but using batteries depend on the amount of sunlight that exists.

17. Be accessible to all, especially the poor people.

18.I: A comprehensive awareness campaign; II: Providing good and cheap varieties in the local market; III: Training of municipal technicians and the electricity company on this 
Energy; IV. Support for students studying this specialization.

19.Implementation of electric power generation projects, through solar panels over houses.

20.Provision of appropriate and energy-saving solutions in the area of heating, especially for the high cost of fuel or electricity, which are frequently used as a fuel source and heating in winter.

21.Reducing the cost of renewable energy.

22. The government must facilitate the process of alternative energy procedures and encourage citizens to install alternative energy and reduce the cost.

23. Spreading the concept of renewable energy more broadly and more practical.

24. Spreading the need to use of solar cells on surfaces.

25.Raise awareness and disseminate information about it and thank you.

26. Mainstreaming the use of renewable energy systems at various social levels to sensitize all segments of society about their importance.

27.Establishment of energy production farms in a pioneering manner and within organizations and in technical ways that ensure the equivalent of supplying the entire area with electricity or at least initially alive.

28. The government must support this project.

29. Let the market make the decision on RE\&EE.

30.Encouraging municipalities to establish renewable energy projects.

31.Establishment of inverters and solar cells factories in Jordan at an affordable price.

32.Using motion detector for lighting.

33. There are organizations and associations that financially support the extension of solar cells to homes and businesses because their delivery and its installation is materially expensive and the electricity bill reduces the use of unfit land for the cultivation of solar cells and windmills to take advantage of wind power.

34. The use of the roofs for fuel stations, especially in desert areas, to enable the owners of electric vehicles to ship during foreign flights. Energy auditing has worked for old government institutions and buildings such as some universities. Exploitation of desert land East and south of Jordan with high solar radiation and low price.

35.Interest in wind energy, reduce the changes in the electricity grid and change the protection codes to suit the variables.
36. Work to expand the network to accommodate more renewable energy projects.

37. Exploiting the wind and the sun to produce energy and reduce the cost to the citizen.

\section{CONCLUSIONS}

The results suggest that in-depth understanding of renewable energy technologies varies markedly. About $(53 \%)$ of respondents are willing to buy PV mobile charger depending on its life cycle and efficiency even if it is expensive. About (89\%) respondents have realized that it is important to develop and support the EE innovative solution of using sodium regulator in lighting the streets by the municipalities, and about (49\%) of the respondents would like to take practical steps for the RE and EE developments if they could. However, this survey showed that the respondents are not always familiar with the difference between RE and EE.

The results also show that all respondents are willing to pay extra cost to obtain green energy; $(20 \%)$ want the cheapest possible solution in this regard. A large percentage of respondents (63\%) think that public sector should take the first step towards renewable energy production. More specifically, the study results indicate that Jordanian people do expect more from the public sector about renewable energy production.

In order to increase the awareness and acceptance of the RE and EE in the society, the government should take measures to broaden the knowledge of children and youth on environmental protection and renewable energy technology, by taking an initiative to modify the curriculums to provide the right information. Through focusing on the socio-economic impacts of their technologies in terms of job creation, improving the environmental and health conditions, increasing the GDP (Gross Domestic Product) ... etc. consequently, facilitate the transition toward the RE and EE systems in Jordan.

In order to promote purchasing and using of the illustrated innovative solutions (PV mobile charger and the Sodium light regulator), or any other innovative solutions that aim encourage the investment in RE and EE sector by the people in Jordan, a specific framework for adopting and implementing innovative solutions must be developed at national level in order to find a legal and strong market for these types of innovations. 


\section{Acknowledgements}

We would like to express our deep appreciation and gratitude to all individuals and entities who supported us to complete this interesting research. Great thanks to DESIR project for giving us the opportunity to work on this important topic for Jordan.

\section{REFERENCES}

1. Ahn S. 2014. An Evaluation of Green Manufacturing Technologies Based on Research Databases. International Journal of Precision Engineering and Manufacturing - Green Technology, 5, Vol. 1, No. 1, 5-9.

2. Al-Mashhadan Y. and Attia H. 2014. Novel Design and Implementation of Portable Charger through Low-Power PV Energy System. Advanced Materials Research, 925, 495-499.

3. Bayer P., Dolan L. and Urpelainen J. 2013. Global patterns of renewable energy innovation, 19902009. Energy for Sustainable Development 17, 288-295.

4. Becker D. and Tawalbeh M. 2013. National Energy Efficiency Action Plan. http://www.rcreee. org/sites/default/files/plans_neea p_jordan_2013_ en.pdf.

5. Beermann J. and Tews K. 2017. Decentralised laboratories in the German energy transition. Why local renewable energy initiatives must reinvent themselves, In Journal of Cleaner Production, 169, 125-134.

6. Böhringer C., Cuntz A., Harhoff D., and AsaneOtoo E. 2017. The impact of the German feed-in tariff scheme on innovation: Evidence based on patent filings in renewable energy technologies. Energy Economics, 67, 545-553.

7. Büyüközkan G. and Güleryüz S. 2016. An integrated DEMATEL-ANP approach for renewable energy resources selection in Turkey. International Journal of Production Economics, 182, 435-448.

8. Electricity legislations, http://www.emrc.gov.jo/ index.php/en/legislationregulatory-doc/renewableenergy-sector-doc.

9. F. R. Blánquez, E. Rebollo, F. Blázquez and C. A. Platero, 2013. High-Efficiency Voltage Regulator and Stabilizer for Outdoor Lighting Installations.

10. Hewitt R., Nick P. Winder, Jiménez V., Alonso P., Bermejo L. 2017. Innovation, pathways and barriers in Spain and beyond: An integrative research approach to the clean energy transition in Europe, In Energy Research \& Social Science, 34, 260-271.
11. Hype cycle, 2013. "Hype Cycles ," http://www. gartner.com/technology/research/hypecycles.html.

12. IEA, 2010. Electricity Information 2010.Technical Report, International Energy Agency.

13. Ministry of Energy and Mineral Resource, http:// www.memr.gov.jo/Pages/viewpage.aspx?pag $\mathrm{eID}=264$.

14. Moula M., 2012."Street children and services: a qualitative study of street children in the context of service delivery system in Bangladesh", Pattern of Data Analysis, Department of social sciences, University of Helsinki, Finland.

15. Moula M., Maula J., Hamdy M., Fang T., Jung N. and Lahdelma R. 2013. "Researching social acceptability of renewable energy technologies in Finland", International Journal of Sustainable Built Environment 2, 89-98.

16. Noailly J., Smeets R. 2015. "Directing technical change from fossil-fuel to renewable energy innovation: An application using firm-level patent data", Journal of Environmental Economics and Management, 72, 15-37.

17. OECD (2016), OECD Science, Technology and Innovation Outlook 2016, OECD Publishing, Paris

18. http://dx.doi.org/10.1787/sti_in_outlook-2016-en

19. Sodium Light unit, 2017. http://www.orbis.es/doc/ memoria_esdoni_ing.

20. Sustainable energy technology; Flywheel energy storage; Short-term storage; Batteries; Kinetic energy recovery system ,http://www.memr.gov.jo/ EchoBusV3.0/SystemAss ets/PDFs/AR/Taqa $\% 20$ 2016\%20Arabic.pdf.

21. Synergies between Renewable Energy and Energy Efficiency, 2015. https://www.irena.org/-/media/ Files/IRENA/Agency/Publication/2015/IRE NA_ C2E2_Synergies_RE_EE_paper_2015.pdf.

22. Tawalbeh M. 2016. Energy Efficiency; Current Trends and Future Perspectives in Jordan, http:// www.cres.gr/kape/publications/pdf/mare_20 16/12_Tawalbeh.pdf.

23. U.S. Energy Information Administration (EIA), 2014. "Jordan international energy data and analysis. http://www.eia.gov/beta/international/analysis. cfm?i so=JOR.

24. Varadarajan M.S. 2012. "Coin Based Universal Mobile Battery Charger" IOSR Journal of Engineering (IOSRJEN)ISSN: 2250-3021 Volume 2, Issue 6 , PP1433-1438, www.iosrjen.org

25. Wicki S. and Hansen E. 2017. Clean energy storage technology in the making: An innovation systems perspective on flywheel energy storage. Journal of Cleaner Production, 162, 1118-1134.

26. Xiao W., Dunford W., Palmer P.. and Capel A. 2017. Regulation of Photovoltaic Voltage. IEEE Transactions on Industrial Electronics, 54(3). 